To link to this article / Para enlazar con este artículo:

https://doi.org/10.14198/fem.2020.35.08

To cite this article / Para citar este artículo:

O'Hagan, Angela. «Bacchi as pedagogy: Surfacing equality and human rights in public policy teaching». En Feminismo/s, 35 (junio 2020): 207-232. Monographic dossier / Dossier monográfico: A critical practice of thinking otherwise: Bacchi, Gender and Public Policy Analysis, coord. Angela O'Hagan, DOI: 10.14198/ fem.2020.35.08

\title{
BACCHI AS PEDAGOGY: SURFACING EQUALITY AND HUMAN RIGHTS IN PUBLIC POLICY TEACHING
}

\author{
BACCHI COMO PEDAGOGÍA: LA IGUALDAD Y \\ LOS DERECHOS HUMANOS EN LA ENSEÑANZA DE \\ LAS POLÍTICAS PÚBLICAS.
}

\author{
Angela O'HAGAN \\ Glasgow Caledonian University, Glasgow \\ Angela.OHagan@gcu.ac.uk \\ orcid.org/0000-0002-6130-8186
}

\begin{abstract}
Understanding the structural dimensions of inequality, and reflecting on our own assumptions and the presuppositions and knowledge basis of the institutions we work in is key to a critical approach to management and to learning. That is the central argument of this article which demonstrates the application of Bacchi's 'What's the Problem Represented to be?' framework in the learning, teaching and assessment in a post graduate programme on Citizenship and Human Rights. Based on critical theories in feminism, disability, racism, globalisation and human rights, the programme aimed to support «practitioner students» in acquiring new theoretical knowledge and applying that to their organisational practice. Reflecting on current practice and procedures and thinking backwards from current ways of thinking and doing, students were encouraged to «critically engage in thinking otherwise», as exhorted by Bacchi. Through this critical engagement with theory and practice, student practitioners could then «surface» the equalities and human rights dimensions and tensions in their work.
\end{abstract}

Keywords: Equality; Human rights; Public policy; Social justice; Feminism.

Los contenidos de la revista se publican bajo una licencia de Creative Commons Reconocimiento 4.0 Internacional (CC BY 4.0)

Feminismo/s 35, junio 2020, pp. 207-232 


\section{Resumen}

Comprender las dimensiones estructurales de la desigualdad y reflexionar sobre nuestros propios supuestos y las presuposiciones a la base de conocimiento de las instituciones en las que trabajamos es necesario para un enfoque crítico de la gestión y el aprendizaje. Ese es el argumento central de este artículo, que demuestra la aplicación del marco Bacchi «¿Cómo se ha representado el 'problema'?» en el aprendizaje, la enseñanza y la evaluación en un programa de posgrado sobre Ciudadanía y Derechos Humanos. Basado en teorías críticas sobre feminismo, discapacidad, racismo, globalización y derechos humanos, el programa tuvo como objetivo apoyar a los «estudiantes practicantes» en la adquisición de nuevos conocimientos teóricos y aplicarlos a su práctica organizacional. Al reflexionar sobre la práctica y los procedimientos actuales y «pensar hacia atrás» desde las formas actuales de pensar y hacer, se alentó a los estudiantes a "comprometerse críticamente a pensar de otra manera», como lo exhortó Bacchi. A través de este compromiso crítico con la teoría y la práctica, los estudiantes practicantes podrían entonces «hacer surgir» las dimensiones y tensiones de igualdad y los derechos humanos en su trabajo.

Palabras clave: igualdad; derechos humanos; políticas públicas; justicia social; feminismo.

\section{INTRODUCTION}

In 2010, Glasgow Caledonian University (GCU) introduced an MSc in Citizenship and Human Rights. This programme was developed to meet a need among social justice practitioners working in civil society and public sector organisations to support in-work practice by enhancing the underpinning analytical capacity and conceptual knowledge base of practitioners. At the time there were a number of positive drivers for a programme of this type. The Public Sector Equalities Duties were being introduced under the Equality Act 2010, building on the previous positive duties and emphasising the transformational potential of engaging institutional policy and decision making processes in equalities analysis (Hepple 19). Furthermore, the underpinning for the new legislation drew heavily on the capabilities approach (Burchardt and Vizard 91), which was also featured in the course content and design of the MSc syllabus and learning outcomes.

This innovative programme at GCU was international in scope and intent, reflecting the global commitments around the Millennium Development 
Goals (MDGs) initially and then moving to the SDGs from 2015. There was also a significant domestic content within the programme as the devolution of powers to the Scottish Parliament created an ongoing process of policy development and structural change. This local context of the development of a small nation, growing its autonomous (devolved) competences since 1999, and building a distinctive discursive narrative around equality and human rights reflected ambitions of transformational and alternative policy making (O'Hagan, «Favourable» 234). The domestic political discourse was framed around aspirational policy objectives to integrate equality and human rights, and from the inception of the Scottish Parliament, a rhetorical drive in public policy on basing practice and improved outcomes on social justice goals (Scott and Mooney 380; O'Hagan, «Perspectives» 229). This was increasingly reflected in the rhetoric and service design in public and third sector organisations and their expressed desire for changes in practice.

Emma Coles et al. describe this approach as «a whole policy/whole country implementation and national transformational change agenda» (336). For these scholars, the focus is specifically in relation to the wellbeing of children, but the aspirations ranged across all social, and to some degree economic policy domains as

Scotland has attempted to further its aspirational agenda based on the desire to create a socially democratic society while at the same time addressing Scottish needs and the Scottish national interest and following principles of social justice (339)

This policy context and the drive to improve practice in equality and human rights, locally and globally, was the background for the MSc in Citizenship and Human Rights. The programme was designed for and with policy analysts, client-facing service managers, equality and diversity officers, and other policy advocacy roles within third and statutory organisations, initially with the support of the Scottish Council for Voluntary Organisations (SCVO). The first cohort also attracted funding support through the European Social Fund to facilitate participation from practitioner students based in the Scottish Highlands and Islands. The post-graduate students on this programme were not recent graduates. Some had no first degrees, and for others their first degrees had been achieved 20-plus years ago. All of the students were in work 
in a range of roles across third sector service delivery, civil society advocacy, local and statutory authorities, and even one student from an industry professional body with members largely located in the private sector. In recognition of that experience, and that this programme was designed as a «work-based» programme, when referring to «students» throughout this article, I characterise them as «practitioner students».

This article sets out the application of feminist theoretical and policy analysis as a core theoretical pillar of the MSc programme and discusses the theoretical concepts in play in relation to feminist analysis. Feminism was not the only critical theoretical framework in the programme, but is the principal focus of this article. Following a brief introduction to the programme structure, the article introduces Bacchi's What's the Problem Represented to be (WPR) framework as a structure for applied learning for practitioner-students. The main evidence presented and discussed here are the findings from student coursework and reflexive journals. The article focuses on the use of WPR as an analytical process that reveals androcentric and other normative approaches to organisational practice and policies and the implications of the established ways of thinking and doing of governmental policy for implementation in diverse social policy related organisations. The article concludes with observations on the application of the WPR framework as a heuristic within reflexive pedagogy in the context of critical management education.

The principal contribution of this article is the presentation of how practitioner-students in a post-graduate programme on Citizenship and Human Rights acquired new knowledge that both challenged and reaffirmed some of their existing knowledge on equality and human rights from a range of critical theoretical perspectives. Core to the principles of the programme, as a form of critical management education, was a framework of critical theory on gender, race, disability, globalisation and migration, and human rights. This article describes the approach in two modules to learning, teaching, and doing through engaging students in reflexive processes that revealed what Bacchi and Goodwin (13) describe as different ways of thinking about «commonly accepted categories and governing practices». 


\section{CREATING A CRITICAL LEARNING COMMUNITY}

In designing a post-graduate curriculum for work-based learning for students from social policy and social service organisations, learning, teaching and assessment had to be cognisant of the wealth of experiences such students bring from their personal and professional lives. As established in the critical management education literature summarised by Hibbert «the effective learning of such processes seems to depend on students having substantial experience to explore, critique, and reconsider in order to facilitate critical reflection on their own management lives» (805).

With students from Scotland and other countries; from third, statutory and private sectors, perspectives were mixed and organisational focus varied considerably. From the outset then, the aim of the programme was to be inclusive in relation to age, disability, location, gender and ethnic identity, and educational background. This range of perspectives brought a wealth of knowledge and practical experience to the programme and to the individual modules in the real and virtual classrooms. This diversity of experience and perspective was an important element in establishing a critically engaged community of learning, consistent with what Hibbert (808) and others have described as a «community feel» in the physical and virtual classroom. A further challenge in creating a community of learning and practice was that the programme was a combination of on-line and face-to-face delivery. The majority of «lecture» and learning material was provided through an online blackboard, supplemented by use of other accompanying technologies such as wikis, virtual discussion boards, and on-line journals. Each module included four full days of face:face engagement with students and tutors at the start and towards the end of the module.

\subsection{Citizenship and Human Rights in a work-based context}

The rationale for the Masters was to create a programme for learning that would underpin the principles of social justice that practitioners in third and statutory sectors aimed to be working to by providing both theoretical structure and challenge to establish norms. There was an explicit intention to link human rights principles to management and organisational practices 
that not only was consistent with expressed institutional commitment to the «common good» and the UN Global Compact Principles of Responsible Management Education (PRME) but which more substantively stemmed from an epistemological view of the world and an awareness of the unequal lived effects as a consequence of dominant economic paradigms and political structures.

The MSc in Citizenship and Human Rights was initiated in 2010, just as the effects of the politically constructed austerity measures in response to the financial crash of 2008 were beginning to be enacted by governments in the UK and globally. A central pivot of austerity measures was the systematic withdrawal of public spending from public services, social security and social protection measures, and an emphasis on such as a means of reducing levels of national debt and the deficits in public finance.

This context provided multiple pathways for policy analysis and interrogation within classroom discussion. It also meant that as public services were dismantled and existing inequalities exacerbated, practitioners in the third and statutory sectors came under increasing pressure to deliver services and augment their advocacy. At the same time, their training and professional development budgets were lost, resulting in small numbers accessing a programme like this masters, however innovative it was at the time. The programme ran for almost ten years, albeit with small student cohorts but whose ability and levels of engagement compensated for the lack of numbers.

Our MSc in Citizenship and Human Rights was developed to meet a need among social justice practitioners working in civil society and public sector organisations. A core intention of the programme design and content, was to surface what Bacchi (Women 7) describes as «lived effects», that is, the diverse ways in which people experience how policy makers represent problems and policy decisions in their everyday lives. Drawing on critical theories of disability, race, feminism, globalisation, and the application of alternative theories of social, legal and economic justice such as the Capabilities Approach (Sen; Nussbaum) and Fineman's conception of vulnerability, students were encouraged to engage in what Bacchi and Goodwin describe as the «critical practice of thinking otherwise» (21). 


\section{INTRODUCING BACCHI}

Central to the learning and teaching on the programme was a very clearly expressed intent to encourage learners in the critical practice of «thinking otherwise» as Carol Bacchi exhorts policy analysts and others to do in her What's the Problem Represented to be (WPR) framework. The WPR framework was not used in all modules in the programme: it structured work-related change projects and reflexive journals in the modules on Human Rights and Leadership for Equality. The structure of learning and applying the Bacchi framework and the insights from practitioner-student coursework form the central focus of this article.

\section{DEVELOPING CRITICAL THINKING IN SOCIAL JUSTICE PRACTICE}

This next section locates the feminist theoretical approaches that underpinned the learning, teaching in the modules that used the Bacchi WPR approach for assessments. Other critical theories structured the MSc programme, but as a feminist academic activist, my teaching is informed and shaped by an overarching framework of feminist theory from a mainly radical feminist perspective. As a gender budgeting and feminist policy analyst, the curriculum I delivered within Leadership for Equality and Human Rights modules predominantly featured an applied feminist economics and feminist institutionalist approach to analysis and representation of the intersectional lived effects of policy decisions on people's everyday lives.

Foundational concepts for an approach to orientate students towards critical theory with a focus on the transformational intent and potential of a radical feminist approach, included returning to Squires (7), the discursive dimensions of gender equality (Lombardo, Meier, and Verloo), and further Bacchi («Intentionality») including her propositions of «reflexive framing».

\subsection{Feminisms and transformational change}

Thinking about feminism as a «travelling concept» Lombardo, Meier and Verloo (1) remind us that the concept and practice of «feminism» is open to and reflective of different meanings, experiences and perspectives. The discursive exploration of gender equality meanings, institutional structures, policy making and framing, aligns with Bacchi's WPR approach and her discussion 
of «reflexive framing» in advocacy and policy making around gender equality. Bacchi encourages «reflexive introspection on the systems of thought ('discourses') influencing 'ways of arguing' ('frames'), or 'reflexive framing' as necessary to prevent the development of agendas and proposals that may well help some women at the expense of others» (Bacchi, «Intentionality» 28).

Our approach to learning, teaching, assessment and research overall in the MSc programme could be characterised as an attempt to encourage students to «catch oneself 'in the act of seeing in particular ways'-[where] it is crucial to ensure that the perspectives and embodied experiences of diverse and often under-represented groups are foregrounded» («Intentionality» 29). Central to this analytical approach from a feminist theoretical and policy analysis perspective was what Squires has characterised as a strategy of «displacement» (8). In what is a caveat for those engaged in governing -at a political or organisational level-, Squires cautions us to be alert to the implicit peril of losing a focus on voice (recognition) and the potential for «marginalizing rights-based gender equality arguments and side-lining more democratic participatory approaches to its pursuit» (2). Squires' challenge is that gender equality analysis and policy making needs to avoid the pitfalls that can arise within the «pursuit of equal treatment and the recognition of difference» (9). The presumption of equal treatment still persists within androcentric norms, potentially resulting in a less transformative assimilation of women into established institutional norms, rather than the second option of a 'strategy of reversal' through asserting difference. Squires calls for a third strategy. Her proposition for «displacement» (10) aims to break down existing institutional norms; the ways of thinking and doing established in the path dependencies of political and governmental institutions. The transformation of norms and institutions themselves, is central to wider, more diverse and democratic engagement. Twinned with the WPR and «reflexive framing» from Bacchi, students were supported in revisiting their professional experience and unpicking, even unpacking, some of their own established practice and ways of thinking.

In deconstructing Squires' theoretical challenges, it was useful to draw on the more didactic explanations of different approaches, generations, even of gender equality policy analysis. What Rees described as «tinkering, tailoring 
and transforming» (19) in relation to equal treatment, equal opportunities, and gender mainstreaming, Bagilhole further breaks down as

- Equality of opportunity is the «equal access to institutions and social positions among social groups;

- Equality of condition, the starting point determining access to opportunity, the life circumstances question;

- Equality of outcome, is concerned with alternative approaches and arrangements for different social groups «in order to transform inequalities of condition at the beginning into equalities at the end.» This may require special measures, so-called 'favourable treatment', or positive action as allowed in equality legislation. (141)

Hepple moves us on conceptually into the era beyond formal equality before the law, into an aspirational era of transformation whereby institutions, rather than those with particular characteristics, are the central focus of change. This conception of equality, and particularly of the function of legislation emerging from the mid 2000's is for a transformative equality, whereby systemic and structural inequalities are broken down and poverty and other disadvantage are eliminated.

This development of legal thinking and treatment beyond the basis for unequal or discriminatory treatment to consideration of the impact of decisions or actions was the basis of the Equality Act 2010 in Great Britain, which is broadly similar to the Ley de Igualdad 2007 in Spain. Both place a duty on public authorities to reflect on their own practices and what information and knowledge informs decision making. Such reflexive legislation had -and continues to have-significant transformational promise, should the political will and institutional competence exist to support further community participation in public service design (Conley).

\subsection{Vulnerabilities}

Situating the lived and discursive effects of policy decisions upon everyday lives and diverse circumstances is central to a university social and economic justice programme. The curriculum and learning outcomes clearly evidence an approach that sought to balance content on the institutional frameworks and levers for the realisation of human rights through international and domestic law with theoretical and conceptual underpinning on 
theories of justice. In addition to the overviews of Rawls' Theory of Justice, Sen's Capabilities Approach, and Nussbaum's developments in 'Gender and Social Justice', Martha Fineman's «vulnerability approach» was introduced as another route in to thinking backwards from current policies and the problem representations therein. As a feminist legal scholar, Fineman expands from the protection of rights and the role of the state to a reconceptualization of human rights, with the emphasis on the human. Fineman encourages us to think about human life and experiences as vulnerable, whereby there is a constant possibility of «harm, injury or misfortune» (28).

As Bjørnholt and McKay discuss (8), vulnerability is both universal and constant, and particular. As individual humans we experience vulnerability differently depending on the inter-related «webs of economic and institutional relationships» and «the quality and quantity of resources we possess or can command» (Fineman 31). Our vulnerabilities are complex and one form can cause further harm in other ways, such as economic collapse or illness that leads to unemployment and subsequent poverty. Vulnerability also manifests and has different implications for individuals on the basis of other societal institutions and behaviours, such as different and unequal treatment on the grounds of disability, gender, race, age and other characteristics. It is the role of law and state institutions, Fineman argues, to prevent the harm from such actions, to which we are all vulnerable in different degrees and at different times. Consistent with concepts of capabilities and functionings from Sen and Nussbaum, Fineman suggests that individuals can build resilience to these harms through «having some means with which to address and confront misfortune» (32). These means are to a large extent provided by societal institutions and include assets or resources: physical resources, human resources, social assets or resources, ecological resources and existential resources. Fineman is concerned with «privilege and favor conferred on limited segments of the population by the state and broader society through their institutions» (23), including the labour market, the family, education systems and other institutional frameworks, which Bjørnholt and McKay emphasise as «institutions [that] play a core role in allocating resources, and are pivotal in the production of privilege and disadvantage» (8).

These conceptual perspectives support the assertion that gender is a social construct, which Bradley explains as

Feminismo/s 35, junio 2020, pp. 207-232 
the varied and complex arrangements between men and women, encompassing the organization of reproduction, the sexual divisions of labour and cultural definitions of femininity and masculinity. It therefore is, at one and the same time, a set of social arrangements determining how women and men live, and a way of thinking which divides people up into two (or sometimes more) social categories. (16)

Recognising and understanding the effects of these multiple social categories and the gendered relations within formal and informal institutions which create the «structural constraints» that Folbre has described, were central to the curriculum. The theoretical background summarised in this section, formulated the analytical approach to learning, reflection and assessments using the WPR approach, in two specific modules, as explained in the following section.

\section{APPLICATION OF THE WPR FRAMEWORK IN COURSEWORK}

We wanted, and still desire, our students to be able to describe theory as well as apply it and critically analyze it. In this way, our approach was consistent with the Bacchi WPR framework and its aim of opening «a new space for the active involvement of policy workers or analysts in contestation over the substantive content of policies» as described by Bacchi and Goodwin (61). The WPR approach is a "way of thinking differently about commonly accepted categories and governing practices» (Bacchi and Goodwin 13) and, as they suggest, is relevant to students of sociology, social policy, and social work. The WPR, therefore provided a theoretical and analytical framework consistent with critical study and engagement in social justice policy and practice, relevant for practitioner students from a range of social policy, service and advocacy perspectives.

We used the WPR framework on our Human Rights (HRts) and Leadership for Equality (L4E) modules to support student enquiry into their workplace practices to reveal and explore the equality and Human Rights dimensions within. The aim was to surface these as not only central to the practice of our student-practitioners, but to reveal that equality and human rights issues are integral to the purpose, function and design of public services delivered through public sector and third sector organisations. Working through theories of equality, justice, human rights, we developed and delivered a syllabus 
that aimed to move operational practice of equality beyond the more superficial organisational practices of equality of opportunity to bring to the surface an understanding of the structural causes of inequality, discrimination, and their daily manifestations in workplace practice and the systemic absence of an equality analysis informing public policy at all levels.

In using case study as pedagogy in a work-based programme, our aim was to approach teaching and building practice in policy analysis from a post-positivist perspective, looking to the discursive context of decision-making on policy at different levels of organisational and institutional governance. Case study examples were certainly used to illustrate theoretical points, but case studies were a central approach to practical assessed coursework, especially relevant for a work-based, blended learning programme. Again, consistent with a critical management education approach, we used case study in the way described by Foster, McBeth and Clemons, as based on a «broader epistemology» combining political insight, value conflict, subjectivity, and ambiguity with other skill development» (518). As a work-based change project, our students were directed to take an approach, applying Bacchi's WPR framework to a «situation [that] revealed a problem that needed to be solved» (518).

Our approach was one of praxis, where we simply mean «theory guided action», which in turn simply means that students were requested to construct cases that promoted active learning and critical thinking. We used this process in the way that cases may be used to illustrate a process or theory, or they may provide a decision dilemma in the form of a problem to be solved.

Bacchi and Goodwin's contention (16) that «the manner in which 'problems' are constituted shapes lives and worlds» was central to the teaching and to the courses assignments and exercise in which our students engaged in these modules. In a programme on Citizenship and Human Rights, the core focus is on the structural -legal, social, and economic- constraints and conditions that impact different groups of people differently resulting in greater or lesser social, economic, political and civil inequalities.

Formulated as a change project, students were directed to use the WPR framework to formulate a work-based project to develop an area of practice that revealed, or surfaced, an equality and human rights dimension that they had identified as lacking in the existing «representation» of the problem or organisational practice. By taking the WPR, «working backwards» approach

Feminismo/s 35, junio 2020, pp. 207-232 
to problem representation from Bacchi and Goodwin (20), students were to unpick how current organisational practice had been formulated, consider what the «problem» was and how that representation had been arrived at, and what silences and alternative representations had been overlooked in that formulation. As they phrase it: «what we propose to do about something indicates what we think needs to change and hence what we think the «problem» is (16).

\subsection{Applying theory to practice in organisational change case studies}

This was a work-based problems solving exercise, of the approach described by Foster, McBeth and Clemons as the «ability to analyse the political basis of public policy provides them with the necessary analytical skills they need to secure and perform jobs as public administrators and analysts» (519). Students were directed to use and amended and expanded version of the 6-question formulation of the WPR Framework from Bacchi (Bacchi, Women; «Intentionality»; «Problematizations»). Bacchi's framework is set out in Table 1 below.

Table 1. WPR Chart: What's the Problem Represented to be? (WPR approach to policy analysis)

Question 1: What's the problem (e.g. of "gender inequality», «drug use/abuse», «economic development», «global warming», «childhood obesity», «irregular migration», etc.) represented to be in a specific policy or policies?

Question 2: What deep-seated presuppositions or assumptions (conceptual logics) underlie this representation of the "problem»(problem representation)?

Question 3: How has this representation of the «problem» come about?

Question 4: What is left unproblematic in this problem representation? Where are the silences? Can the "problem» be conceptualized differently?

Question 5: What effects (discursive, subjectification, lived) are produced by this representation of the «problem»?

Question 6: How and where has this representation of the «problem» been produced, disseminated and defended? How has it been and/or how can it be disrupted and replaced?

Step 7: Apply this list of questions to your own problem representations.

(Adapted from: C. Bacchi and S. Goodwin)

Feminismo/s 35, junio 2020, pp. 207-232 
The specific instructions for the Human Rights coursework are set out in Table 2.

Table 2: Bacchi WPR Adapted for Human Rights Module Handbook

Assessment 2: Presentation,

'What's the problem represented to be»: Apply Carol Bacchi's policy analysis approach to the relevant work-based issue/problem

Assessment 4: Case study report.

You will need to address the following questions in your case study:

1. What is the problem and how can it be described using the language of human rights?

2. What is the incidence of the problem and what possible data exist?

3. What elements/proportion of the population are affected?

4. How could this problem be justified as a human rights issue using the following three traditions: natural rights, states obligations and the constructed rights tradition?

5. What «cultural relativism» arguments or dilemmas can be associated with this problem and associated human rights? How could these be overcome?

6. How do the problem and the associated rights relate to various structures and discourses of oppression, such as gender, race, class, sexuality, age and (dis) ability?

7. What international instruments exist to safeguard human rights in respect of the problem?

8. What national instruments exist to safeguard human rights in respect of the problem, and how far do they match international instruments?

9. How could this problem be addressed using human rights tools/instruments? What is the scope for, and the limitations of, human rights interventions at the different levels (micro, meso, macro) and with the different orientations/ approaches (remedial, preventative, developmental)?

10. What can be your role and the role of your organisation in addressing this problem?

The Leadership for Equality guidance in Table 3 below draws on the Bacchi framework and the dimensions of interrogating policy representation, the surfacing of the lived realities and subjugated knowledge and silences, and the requirement to reflect on own analytical processes and proposals for change. The work-based change project here extends the reflexive element of the WPR process by including a requirement for self-reflection on the students' proposals in the form of a reflexive journal. The assignment was a four-step process set out in Table 3. Firstly, students were to engage in

Feminismo/s 35, junio 2020, pp. 207-232 
internal inquiry, looking within their own organisation at an issue of interest to them, in the context of how the "problem» was currently represented in terms of what Bacchi and Goodwin (16) call «unexamined ways of thinking around what the organisational response formulated in policy and practice» reveals about how the focus of action had been framed. Using the WPR questions to interrogate and peel back existing assumptions as the knowledge base for action, students applied new learning and epistemological perspectives (feminist, social justice) to explore and interrogate assumptions and presuppositions that had resulted in organisational representations of the problem, asking if the problem could be conceptualized differently. Bacchi and Goodwin argue that this approach helps to «identify the particular combination of practices and relations that give a "problem» a certain shape in a particular context, and indicate that different practices can produce contrasting problematizations» (23).

Following from this understanding, students were to explore with an equalities and human rights lens what was not included or what vulnerabilities, lived effects, or voices had been silenced or rendered invisible in the process that resulted in specific policies, and begin a process of formulating alternatives. This process of considering what had previously not been considered, left unproblematized, is the essential purpose of the exercise, to engage in Bacchi and Goodwin's «critical practice of thinking otherwise» (22). For student practioners this was central to their learning and the application of new knowledge and reflective practice, following what Bacchi and Goodwin present as an «opportunity to be inventive, to imagine worlds in which a specific confluence of circumstances is either not problematized or problematized differently» (22).

Consistent with creating a community feel and reflexive practice within a development community of practice, students presented the outline of their inquiry and early thoughts on reformulation for discussion with students and tutors in face: face sessions. In a supplementary exercise to support the process of revealing the «effects» that Bacchi signals (discursive, subjective, lived), students were encouraged to work through theoretical and practical considerations of research methodology -participative, feminist, reflexive. The purpose of this was to identify the effects of the actual policy 
representation and consider suitable processes to lead to a more inclusive, and accurate, alternative approach to the particular policy or service under consideration.

The fourth and final step comprised two elements:

i. A full report on their analysis of the problem representation, and an exploration of alternative analytical approaches and changes to ways of working and with whom in order to produce policies and services that revealed and engaged with mitigating and limiting the negative effects of previous representations.

ii. A reflexive journal, encouraging reflection on the student learning around knowledge acquisition, alternatives to practice and surfacing values within their organisation, and the potential differences in outcomes of their proposed alternative approach.

\section{Table 3. After Bacchi's WPR - Change for Equality Project}

(1): Outline Project Proposal

This assessment requires you to identify a specific action for change within your work-place, an organisation of which you are a member or an issue where you have identified the need for and potential benefits of change. You are required to outline the specific issue, for example a change in procedure around equality impact assessment; mitigating the impact of policy change -internally or externally imposed; or questions of representation of minority or excluded groups, or representation of equality issues in the media, or a specific action in which you are involved. You are required to set out how you will evidence that your issue, or change project, is of substantive concern. You are required to set out your case for change and the key stakeholders and influencers you are seeking to target. You should also identify the resources -financial, personnel, time, data, information, that you will draw upon in conducting your project.

(2): Presentation of Change Project and Progress Update

Verbal presentation of the change project - objectives, resources, stakeholders involved, and progress to date.

(3): Critical Reflection on Values in Research

This assignment is a short written piece outlining your understanding of the values underpinning research, consultation, and involvement with communities of interest, or local communities in general. 
(4): Portfolio of evidence and reflective learning report. This is the final report of your change project and should evaluate the progress made, levers for change and barriers to progress. It should also include reflective discussion on the theoretical concepts and frameworks explored over the course of the Module and the extent to which they did -or did not- inform and influence your thinking in evaluating your change project. You will not be assessed on the final outcome of your change project as it is to be assumed that some aspects may be beyond your control, and the project takes place within a short period of time. However, you will be assessed on your methodology, structure, use of theoretical constructs and concepts of equality and leadership as discussed throughout the Module.

This application of the WPR framework as a learning and practice development tool exemplifies the principles of critical management education as set out by Hibbert; using a reflexive pedagogy to combine Bacchi's process of critical thinking and working backwards to alternative policy representations. The structure of the assessment and the use of face: face class sessions illustrate Hibbert's four principles:

- Preparing and making space for reflection in the particular class context;

- stimulating and enabling critical thinking through dialogue, in particular in relation to diversity and power issues;

- unsettling comfortable viewpoints through the critical reappraisal of established concepts and texts; and

- supporting the development of different, critical perspectives through ideological explorations and engagement with sociological imagination (804).

\section{EXPLORATIONS, CONTESTATIONS AND REFLECTIONS FROM PRACTITIONER STUDENTS USING WPR}

Students on the programme came from a variety of organisations. These included local authority social work and housing departments, national civil society organisations on refugee and asylum and LBGTQI advocacy and health condition-specific advocacy and service delivery, alongside local third sector organisations for mental health, local volunteering, learning disability support, and other statutory sector organisations at national and regional level in Scotland. Not all their practical coursework was focused on gender equality

Feminismo/s 35, junio 2020, pp. 207-232 
per se, but was informed by the Bacchi framework and wider theoretical underpinning.

This section presents the projects and reflections presented by students. These have been anonymised and other identifying markers including the name of the organisation and year of submission have been removed. The following is a summary in two parts of a selection of the diverse range of project activity in which students engaged, and the reflections on their learning and the application of the Bacchi framework. The project outlines below are summarised from the students' work.

\subsection{Project outlines}

- Amend the data collection to expand our data capture in order to improve equalities monitoring for mental health service design, as identified through Equality Impact Assessment (EQIA) process. The services of the organisation were to be accessible and available across the local community, including to students in secondary (high school) education. However, the proposals to make apparently small changes in criteria of administrative data to reflect diverse gender identities had been challenged by local religious (Catholic) organisations who regarded such questions as inappropriate for secondary school students. The challenges then for the organisation and Student $M$ as service manager were to work backwards from these assumptions and the existing knowledge basis of the opponents, and work collaboratively to reveal and resolve discrimination (Student $\mathrm{M}$ ).

- Building networking capacity across community sector in coalition against welfare reform by examining the «problem representation» of the necessity for cuts to welfare spending. Student $S$ set out to «identify the silences within, including the absence of intersectional gendered analysis of poverty, the causes and lived effects for disabled people; lack of analysis of inter-related/connections between benefits, housing, precarious employment, childcare and other caring roles; and the assumptions evidenced in the UK government's framing of welfare reform» (Student S). 
- Amend educational regulations in Scotland to allow asylum-seeking young people the same access to full-time further and higher education as other young people in Scotland. By working backwards from the regulatory framework and policy statements, Student $C$ sought to reveal the presumptions and assumptions and providing alternative perspectives including the economic case for participation, in addition to social justice arguments and realisation of rights to education, elimination of discrimination and the advancement of capabilities (Student C).

- Through critical engagement with theories of «authentic leadership» and working backwards from the representation of leadership roles and functions within the organisation, Student A aimed to reveal silences about persistent discrimination against women (individuals presenting as female) within an LBGTQ organisation. The approach sought to explore assumptions of inclusivity of leadership programmes which aim explicitly to support diversity and self-realisation within organisational cultures which assume inclusive characteristics but which are not visible in usual practice (Student A).

- In reviewing policy and practice response to diagnosis and support of young people with autism in Scotland, Student P undertook an historical analysis of the representation and public perception of autism. The approach was theoretically complex, engaging in the discursive effects of concepts such as the persistence of «mother blame», and exploring the effects of the role of professional class privilege in problem representations and assumptions that result in granting professionals credibility and the power not to be challenged in their diagnostic, rather than giving voice to the lived experience of the people being diagnosed. Student P's aim was to highlight institutional practices that «distance disabled people from the public sphere and therefore from participation within it». Surfacing these lived and discursive effects, Student $\mathrm{P}$ proposed, should enable their organisation to move to a social model of disabled people's rights through recognising the social construction of oppression of disability through a discursive analysis of the language used about disability (challenge, overcome, tragedy, resilience...). Working backwards from the representation of 
the «problem» of long term conditions revealed a policy in practice that considers disability a problem to be managed by the individual with high (and therefore undesirable) levels of cost to be borne by the state (Student P).

- Review of local training and organisational practice for social work staff working in the protection of vulnerable adults. Student F's approach was working backwards to reveal the assumptions and knowledge base that shaped National Working Group advice on service and training design for Adult Social Work Protection. Applying Bacchi's framework and Fineman's construction of the vulnerable self, this student revisited and subsequently reformulated guidance and staff training on supporting vulnerable adults within the protection of social work services. Using Bacchi's framework to analyse the problem, Student F structured an approach that «shifts the problem from the staff and their training to the state and societal distribution of power and inequality. This has an impact on how identities are constructed» (Student F).

- Student H developed proposals for addressing the «problem» and reconfiguring representation towards making LGTBQ people with dementia visible and their care appropriate to their needs. The approach to surfacing the equalities and human rights issues for practice -and the lived effects for service users-involved revisiting organisational policies so that practice would better recognise diversity among patients and service users in dementia care; and through revealing heteronormative assumptions about people's lives, revise practices to include the diverse sexual orientation and partnerships of individuals. In this way, Student $\mathrm{H}$ was revealing the negative lived effects of discrimination and re-focusing the organisation on the positive altered everyday experience when the lived effects of gay, lesbian, and couples of other sexual identities were included in organisational practice. Using lived effect approach expressed as «The Problem Illustrated Through Practice Experience», Student $\mathrm{H}$ presented vignettes of experience of dementia care of different individuals, «bringing out the silences of unexpressed lived effects of people's lives and the subjugated knowledge and oppression of

Feminismo/s 35, junio 2020, pp. 207-232 
their realities as LGBTQ people who now have dementia and read across with experiences of stigma and discrimination in their lives pre-dementia diagnosis». The findings from these engagements across different members of the staff and services team were used to inform and re-shape client services and family engagement (Student $\mathrm{H}$ ).

- Integrating intersectional and socio economic inequalities into the training and organisational practice guidance of an anti-racism educational charity, for Student M, revealed that using Bacchi's framework identified the significance of poverty in shaping lived experiences. This contrasted with national government and media discourse that pitted «worklessness» against «scroungers» and «migrants», thereby creating conditions of division and inequality (Student M).

- Exploring the impact of Welfare Reform on people with disabilities from a Human Rights perspective by working backwards from the stated aims of the UK Government to introduce a fairer system, Student W aimed to reveal the problem representation by the UK government and how it contrasted with the intention of human rights legislation and practice. Deconstructing the stated policy aims, Student W analysed government texts and the deployment of human rights framing in welfare policy making. The analysis foregrounded the contrasting alternative representations of the problem and the policy response from the UN Committee on Economic, Social and Cultural Rights (Student W).

\subsection{Student reflections}

This section offers some insights into the learning and re-learning that students, some with almost 30 years' professional experience, reflected upon in the informal (not assessed) learning journals that accompanied the project activity. It is clear from these snapshots that students applied a process of critically thinking otherwise about the «problem» they were sighted upon, and worked backwards from their own and their organisation's assumptions. In this way, they developed knowledge to identify alternative practices that were more responsive to the lived effects experienced by their clients or colleagues. 
I critically reflected on the challenges and I have gained new and valuable insights into leading a complex change project. I started out on this equalities change project with a sense of injustice, anger and passion around the issue of welfare reform, and a sense of urgency for networking the third sector. Through learning gained from this module I have now channelled this into a clear and focussed priority action plan which will enable me to lead on change... I was initially overly outcome focused. My understanding of the interconnection between state delivered welfare and the sector's increasing role has been enhanced but I now have a better understanding of welfare reform as an equalities issue and how I can provide strong leadership and encourage third sector ownership of this change agenda... (Student S)

These reflections from Student $S$, are consistent with Bacchi's challenge that formal education on policy making has been overly focussed on «trying to produce students who are problem solvers» (Bacchi, «Problematizations» 23). The focus instead, Bacchi argues, should be on «"problem'-questioning as a form of critical practice» (23) which is what we can see emerge from further student reflections, as explicitly stated in the example from Student $\mathrm{H}$ and Student $\mathrm{F}$ here.

Carol Bacchi's «what's the problem represented to be?» (WPR) approach to analysing policy was particularly useful in helping me to understand the problematisation of inequality in dementia care. This approach validated the feelings of unease and disillusion I had about how [in] equality within health and social care is often represented as something we are trying to fix/ address. It can often seem like 'equalities' work happens in isolation, usually in «addition to» and not in «conjunction with». How we frame what we intend to do to achieve meaningful equality will determine our success. This needs careful consideration and the key to this is co-production. (Student $\mathrm{H}$ )

How a problem is represented and framed has a bearing on the subjectivity of the research. I have informed and influenced my thinking in problem representation using Carol Bacchi's, what's the problem approach? By reframing my research problem, I have deepened my understanding and reconsidered how to take the research forward. Bacchi's approach involves «a commitment to include oneself and one's thinking as part of the 'material' to be analysed» (Bacchi in Bletsas \& Beasley 2012 22). My understanding of the research problem was something I had yet to consider and in order to effectively support staff to work in an empowering and person centred way with adults who are at risk of harm, it was important to get the design of evidence based learning right. Deep routed societal issues can be enhanced

Feminismo/s 35, junio 2020, pp. 207-232 
or exacerbated by policy development and the way that policy is enacted by staff in practice. Public sector workers are powerful conductors of policy who can inadvertently perpetuate an unequal distribution of power. Without «reflexively of one's own representation of the «problem», I risked doing this myself.» (Student F)

Using questions in WPR framework to identify scope of «problem», where «power» lies in relation to decision making on resources where, Student P argued

People with autism are subjectified as users of services while professionals are cast in the position to take action. People with Autism and their families are subjects, to be consulted with at best. Similarly, the vision of the strategy portrays individuals with Autism as passive bystanders in their own lives by stating «our vision is that individuals on the autistic spectrum are respected, accepted and valued by their communities and have confidence in services to treat them fairly so that they are able to have meaningful and satisfying lives». This vision implies that individuals are only able to fully realise their lives while being in receipt of services and makes no mention of individual capacity or agency to affect chance. There also are tensions present in the document between a conception of the «autism community» and individual needs». Citing Bacchi («Policy»), student P concluded that «representation of policy solutions to the 'problem' lie with the individual and not with society or the structures of the labour market or other institutions, and the dominant silence is that of the voices of people with autism».

\section{DISCUSSION AND CONCLUSION}

In this article, I have engaged in a detailed presentation and discussion of a specific set of coursework assignments that were structured around Bacchi's What's the Problem Represented to be? framework. As an approach to critical thinking for students, and critical pedagogy in management education, it is clear that reflexivity as working backwards as part of the Bacchi process, is what Hibbert has described as

a critical examination of our pattern of personal norms and taken-for-granted assumptions, translates something from being used for thinking to being that which we think about. If the patterns of our foundational assumptions change as a result of the process of reflexivity (and if they do not, the process is futile), then the actual process of thinking is also changed (805). 
In encouraging students to engage from a feminist perspective in the endeavour of what Bacchi and Goodwin describe as a «more expansive understanding of politics» (14), students revealed their own established assumptions and those of their organisations. In their learning and practical application, they explored how «problems» are produced by established governing practices at the level of organisation and political institutions. Following Fineman, this approach engaged students in analysis of policy and practice as a means of «interrogating the institutional practices that produce the identities and inequalities in the first place» (13), as Student F above, among others, reinforced in her reflections.

The overall objectives of this Masters programme and the constituent modules was to bring concepts of social and economic justice, equality, rights and freedoms to the centre of learning, teaching and practice for student practitioners to develop a critical underpinning to their management and organisational practice. The approach to assessment and practical application of the critical theories in play produced analysis through the WPR approach that directly mirrored Fineman's exhortation that

The promise of equality must not be conditioned upon belonging to any identity category, nor should it be confined to only certain spaces and institutions, be they deemed public or private. Equality must be a universal resource, a radical guarantee that is a benefit for all. We must begin to think of the state's commitment to equality as one rooted in an understanding of vulnerability and dependency, recognizing that autonomy is not a naturally occurring characteristic of the human condition, but a product of social policy (23).

In undertaking the responsibility of educating social policy professionals, our approach, as this article has demonstrated, sought to develop student practitioners' approach to thinking critically. In the Leadership for Equality and Human Rights modules, through theoretical and conceptual learning and through reflexivity -essential in the Bacchi WPR approach-students and tutors were engaged in a process of surfacing equalities and human rights issues akin to what Hibbert has described as «intrinsic to the emancipation of thinking and the overcoming (or at least recognition) of the most deeply hidden influences and constraints: those hidden within our own assumptions» (804). 


\section{REFERENCES}

Bacchi, Carol Lee. Women, policy and politics: The construction of policy problems. London: Sage, 1999.

Bacchi, Carol. «Policy, theory, politics: Problem representations in drug and gambling policy.» International Summer School on Inequality and Addictive. 2006. http://hdl. handle. net/2440/57267.

Bacchi, Carol Lee. «The Issue of Intentionality in Frame Theory: The Need for Reflexive Framing». In The Discursive Politics of Gender Equality: Stretching, Bending and Policymaking. Eds. Emanuela Lombardo, Petra Meier \& Mieke Verloo (eds.). London: Routledge. 2009. 19-36.

Bacchi, Carol. «Why study problematizations? Making politics visible.» Open journal of political science 2.01 (2012): 1.

Bacchi, Carol, and Susan Goodwin. Poststructural Policy Analysis: A Guide to Practice. New York: Palgrave Macmillan. 2016.

Bagilhole, Barbara. Understanding equal opportunities and diversity: the social differentiations and intersections of inequality. Bristol: The Policy Press, 2009.

Beasley, Chris, and Angelique Bletsas. Engaging with Carol Bacchi. Strategic interventions and exchanges. Adelaide: University of Adelaide Press, 2012.

Bjørnholt, Margunn, and Ailsa McKay, eds. Counting on Marilyn Waring: New advances in feminist economics. Bradford, ON: Demeter Press, 2014.

Bradley, Harriet. Gender. 2nd ed. Cambridge: Polity Press, 2013.

Burchardt, Tania, and Polly Vizard. «'Operationalizing' the capability approach as a basis for equality and human rights monitoring in twenty-first-century Britain.» Journal of Human Development and Capabilities 12.1 (2011): 91-119. Coles, Emma, Helen Cheyne, Jean Rankin, and Brigid Daniel. «Getting It Right for Every Child: A National Policy Framework to Promote Children's Well-being in Scotland, United Kingdom.» The Milbank Quarterly 94. 2 (2016): 334-365.

Conley, H. «Gender equality in the UK: Is reflexive and responsive legislation the way forward?». In Gender and Diversity Studies in European Perspectives. Eds. Ingrid Jungwirth \& Carole Bauschke-Urban. Verlag Barbara Budrich. 2016.

Fineman, Martha Albertson. «The Vulnerable Subject: Anchoring Equality in the Human Condition». Yale Journal of Law E Feminism 20.1 (2008): 1-23.

Folbre, Nancy. Who pays for the kids?: Gender and the structures of constraint. London/ New York: Routledge, 1994. 
Foster, Richard H., Mark K. McBeth \& Randy S. Clemons. «Public Policy Pedagogy: Mixing Methodologies Using Cases». Journal of Public Affairs Education, 16.4 (2010): 517-540.

Hepple, Bob. Equality: The legal framework. Oxford: Hart Publishing, 2014.

Hibbert, Paul. «Approaching reflexivity through reflection: Issues for critical management education». Journal of Management Education 37.6 (2013): 803-827. Lombardo, Emanuela, Petra Meier, and Mieke Verloo (eds.). The discursive politics of gender equality. London: Routledge, 2009.

Nussbaum, Martha. «Capabilities as Fundamental Entitlements: Sen and Social Justice». Feminist Economics 9. 2-3 (2003): 33-59.

O'Hagan, Angela. «Perspectives on gender equality in Scotland.» In Poverty in Scotland: The Independence Referendum and Beyond. Edinburgh: Child Poverty Action Group, 2014. 229-235.

O'Hagan, Angela. «Favourable Conditions for the Adoption and Implementation of Gender Budgeting: Insights from Comparative Analysis». Politica Economica/ Journal of Economic Policy (PEJEP) XXXI. 2 (2015): 233-252.

Rees, Teresa. "Mainstreaming equality» in Engendering Social Policy. Buckingham: Open University Press. 1999.

Scott, Gill, and Gerry Mooney. «Poverty and social justice in the devolved Scotland: neoliberalism meets social democracy?». Social Policy and Society 8.3 (2009): 379-389.

Sen, Amartya. «Equality of what?». In Tanner Lectures on Human Values. Ed. Sterling McMurrin. Vol. I. Cambridge: Cambridge University Press; Salt Lake City: University of Utah Press, 1980.

Sen, Amartya. Inequality Reexamined. Oxford: Oxford University Press, 1992. Squires, Judith. The new politics of gender equality. Basingstoke: Palgrave Macmillan, 2007. 